\title{
Morbidity and mortality in very old individuals with subsyndromal depression: an 8-year prospective study
}

\author{
Mikael Ludvigsson, 1,2 @ Jan Marcusson, ${ }^{1}$ Ewa Wressle, ${ }^{1}$ and Anna Milberg ${ }^{3}$ \\ ${ }^{1}$ Department of Acute Internal Medicine and Geriatrics and Department of Clinical and Experimental Medicine, Linköping University, Linköping, Sweden \\ ${ }^{2}$ Department of Psychiatry and Department of Clinical and Experimental Medicine, Linköping University, Linköping, Sweden \\ ${ }^{3}$ Department of Advanced Home Care Norrköping and Department of Medical and Health Sciences, Linköping University, Linköping, Sweden.
}

Objectives: Both morbidity and mortality are elevated for individuals with subsyndromal depression (SSD) compared to non-depression (ND) in those of younger ages, but scientific studies are scarce for very old individuals. The aim of this study was therefore to compare the morbidity and mortality in very old individuals with SSD and ND.

Design and setting: An 8-year prospective population-based study was undertaken on 85-year-old individuals in Sweden.

Measurements: Data were collected from postal questionnaires and clinical assessments at baseline, after 1, 5, and 8 years. Depressive symptoms were measured with Geriatric Depression Scale and the results were classified into ND, SSD, and syndromal depression. Mortality was investigated using multivariable cox regressions, and variables of morbidity were investigated using linear mixed models.

Results: Compared to ND, in people with SSD, mortality was elevated in the univariate regression, but this association vanished when controlling for relevant covariates. Morbidity was elevated with regard to basic activities of daily living (ADLs), instrumental ADLs, loneliness, self-perceived health, and depressive symptoms for individuals with SSD compared to ND, whereas cognitive speed, executive functions, and global cognitive function were not significantly impaired when adjusting for covariates.

Conclusions: SSD among very old individuals is longitudinally associated with elevated morbidity but not mortality, when controlling for relevant covariates. Considering the high prevalence of SSD and the demographic development of increasing numbers of very old people, the findings highlight the need to develop clinical and societal strategies to prevent SSD and associated negative outcomes.

Key words: Subthreshold depression, late life depression, elderly, loneliness, longitudinal, cognition

\section{Introduction}

Subsyndromal depression (SSD) or subthreshold depression is a common affective condition that has received increasing attention in the literature during the last decade. The concept of SSD can be described as depressive symptoms below the threshold of what is called a syndromal or a major depressive episode (Meeks et al., 2011). Compared to syndromal depression, SSD is generally associated with lower degrees of impairment and suffering (Ayuso-Mateos et al., 2010), but the relevance

Correspondence should be addressed to: Mikael Ludvigsson, Psykosmottagningen, plan 10, ingång 27, Universitetssjukhuset I Linköping; 58185 Linköping, Sweden. Phone: +46-76-843 8473; Fax: +46-10-103 3894. Email: mikael .ludvigsson@regionostergotland.se. Received 25 Mar 2019; revision requested 10 May 2019; revised version received 03 Aug 2019; accepted 09 Sep 2019. First published online 31 October 2019. of SSD is substantial because of a higher prevalence in the population (Meeks et al., 2011), and consequently, for example, the population-attributable fraction of mortality is comparable between the two (Cuijpers et al., 2013).

As affective conditions vary greatly in intensity over time, longitudinal studies of depressive symptoms have certain advantages for their understanding. SSD compared with non-depression (ND) in old individuals is longitudinally associated with impaired activities of daily living (ADLs; Barry et al., 2009) and cognitive function (Han et al., 2008), reduced self-perceived health (Callahan et al., 1994), worse psychiatric outcomes with higher risk of major depression (Beekman et al., 2002), and higher mortality (Cuijpers et al., 2013). However, few studies have investigated longitudinal outcomes in very old individuals (age $80+$ ). Very old individuals differ 


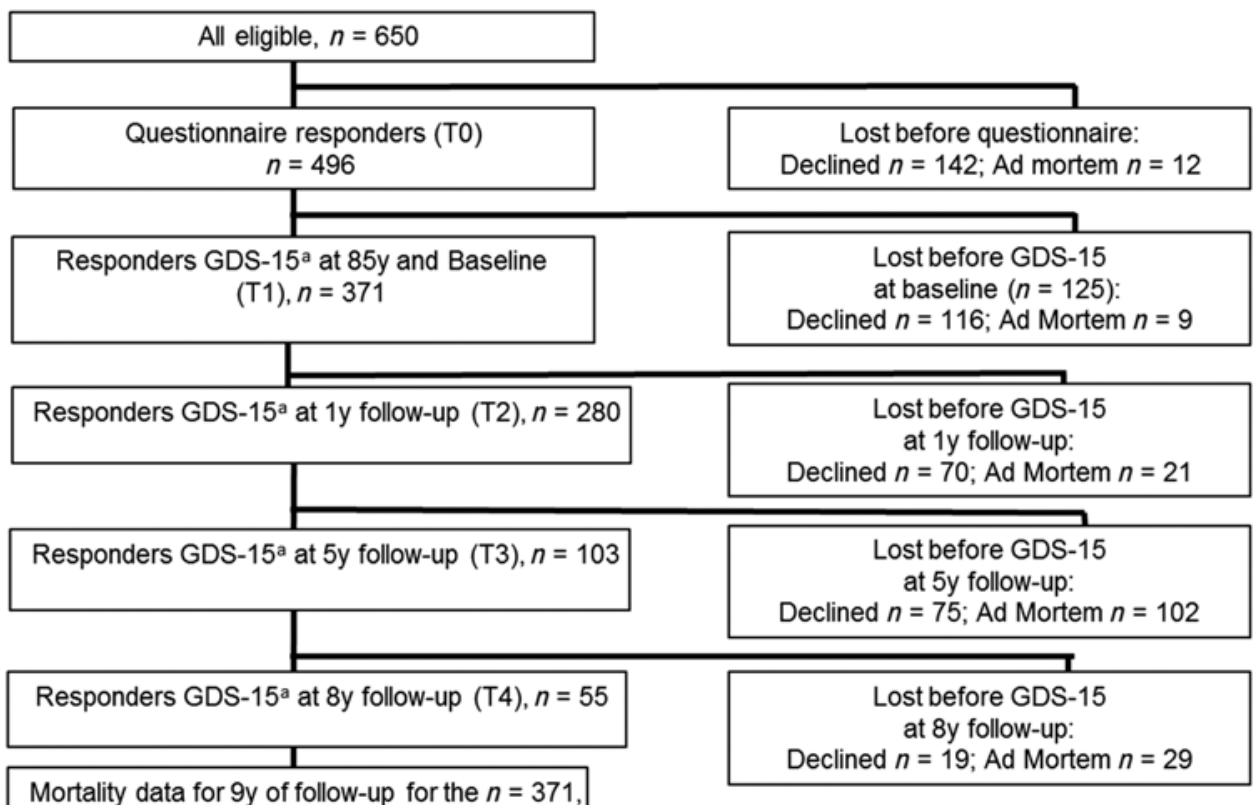

with $n=238$ events, and $n=133$ censored

Figure 1. Derivation of the analytical samples from the Elderly in Linköping Screening Assessment (ELSA-85) study. ${ }^{a}=$ Geriatric Depression Scale (GDS-15) assessment through interview at a home visit.

in general from the young old (age 60-80) with respect to the degree of multimorbidity, frailty, and social dependence.

SSD in the very old has been investigated with respect to natural history (Scafato et al., 2012), psychiatric comorbidity (Laborde-Lahoz et al., 2014), growth trajectories and cohort variations (Yang, 2007), cognitive functions (Han et al., 2008), and mortality (Rapp et al., 2008; Stek et al., 2005). However, to our knowledge only two papers have described outcomes of ADLs (Bacon et al., 2016; Hajek et al., 2017), and none have investigated the development of loneliness in very old individuals with SSD. Moreover, the previous studies on mortality in very old individuals with SSD and depression have shown slightly different results. In the Leiden $85+$ study (Stek et al., 2005), SSD and depression had an effect on mortality only due to loneliness. In the BASE study (Rapp et al., 2008), the effect of SSD and depression on mortality was significant for young old but not for very old individuals, when adjusting for sex and comorbidity.

The aim of the present study was to investigate longitudinal outcomes of SSD in very old individuals. Based on previous studies on SSD in the young old and on syndromal depression in very old age, we hypothesized that in very old individuals, SSD, compared to ND, would be associated with lower function of ADLs (Hajek et al., 2017), worse self-perceived health (Callahan et al., 1994), lower cognitive functions (Han et al., 2008), a higher degree of loneliness (Houtjes et al., 2014), depressive symptoms (Beekman et al., 2002), and higher mortality (Cuijpers et al., 2013).

\section{Methods}

\section{Participants and procedure}

Data were collected from the prospective observational cohort study "Elderly in Linköping Screening Assessment" (ELSA 85), with a population-based design covering 85-year-old individuals in the south of Sweden (Nagga et al., 2012). All individuals born in 1922 and living in Linköping municipality in Sweden $(n=650)$ in 2007 were invited to participate (Figure 1), and no exclusion criteria were used.

Of the 650 eligible individuals, 496 (76\%) provided written informed consent and answered a postal questionnaire (T0). The next phase (T1) of baseline measures included a home visit by an occupational therapist who interviewed 371 participants $(75 \%$ of 496$)$ and performed assessments using the depression screening instrument, Geriatric Depression Scale (GDS-15; Sheikh and Yeasavage, 1986). The baseline phase also included a visit to the local memory clinic where history taking, a medical examination, and administration of cognitive tests occurred. Three additional measure waves were completed: after 1 year (T2), after 5 years (T3), and after 8 years at age 93 (T4), at which questionnaires including the GDS-15 and other 
assessments were readministered. In parallel, information about mortality status and date of death for deceased participants was obtained from the national tax agency from baseline and up to 9 years later, when only $n=133$ (36\%) of the T1 sample were still alive. The present study was approved by the Research Ethics Committee of Linköping University, Sweden (141-06, 2012/332-31 and 2014/455-31).

\section{Measures}

Categories of depressive symptoms: Definitions of SSD vary in the literature (Cuijpers et al., 2013; Meeks et al., 2011). In this study, we chose to define SSD and syndromal depression on the basis of the results from GDS-15 (Sheikh and Yeasavage, 1986). GDS-15 is a valid and reliable self-report screening instrument assessing depressive symptoms in older people, and it contains 15 questions with yes/no answers, where 1 point is awarded for each question (de Craen et al., 2003). In this study, $0-2 p$ were interpreted as having ND, 3-5p were interpreted as having SSD, and $>5 \mathrm{p}$ were interpreted as having syndromal depression (Stek et al., 2006).

Sociodemographic factors: The questionnaire included questions about sex and number of years of education.

Functional abilities: The questionnaires included the self-report instrumental activity measure (Grimby et al., 1998) assessing instrumental ADLs (I-ADLs) through perceived difficulty in the performance of eight different activities on a four-level scale (too difficult (1), great difficulties, some difficulties, and no difficulties (4)): locomotion outdoors, preparing a simple meal, cooking, using public transportation, small-scale shopping, large-scale shopping, cleaning, and washing. These eight values were converted into a single summary score (8-32p) of I-ADLs. Basic ADLs were assessed through questions about the perceived need for assistance in four different activities (bathing/ showering, dressing, toilet visits, and eating) on a three-level scale (need for no (3), little, or much assistance (1)). These four values were converted into a single summary score (4-12p) of basic ADLs.

Self-perceived health status: At home visit, an EuroQol-visual analog scale (EQ-VAS; EuroQol Group, 1990; Rabin and de Charro, 2001) was used. This is a generic instrument that assesses self-perceived health status in terms of EQ-VAS in which the end points are labeled "best imaginable health state" (100) and "worst imaginable health state" (0).

Cognitive functions: The overall cognitive function was assessed with the Mini-Mental State Examination (MMSE; Folstein et al., 1975), cognitive speed was assessed with a composite measure of the sum of the standardized values from Trail Making Test part A (Reitan, 1992) and part one of the Victoria version of the Stroop test (Regard, 1981), and executive functions were assessed with a similar composite measure of the sum of the standardized values from part three of the Stroop test and the Parallel Serial Operations test (Nordlund et al., 2005).

The feeling of loneliness was measured with a single-item, author-constructed question based on a four-level scale of frequency (often (4), sometimes, seldom, or never (1); Park et al., 2013).

Somatic multimorbidity or multiple coexisting chronic diseases were operationalized as the number of chronic diseases from an author-constructed predetermined list of 12 disease categories (Fortin et al., 2012): arrhythmic heart disease, chronic heart failure or myocardial infarction, other vascular disease, hypertension or hyperlipidemia, diabetes mellitus, thyroid disease, respiratory disease, joint disease, central nervous system disease, gastrointestinal disease, urinary incontinence, and malignancy.

\section{Statistical analyses}

The SPSS statistical package (version 23.0) was used for data analyses. Differences in characteristics between participants and nonparticipants were investigated using chi square test and two-sided $t$ tests for each measure wave. Missing values (described more in the results section) were excluded listwise for the analyses. Linear mixed models were used for the longitudinal morbidity analyses because of the large amount of missing data, thereby calculating parameter estimates, $95 \%$ confidence intervals (95\% CIs) and $p$ values. The missing data were not missing at random. Effect sizes of the results were estimated as standardized differences by dividing the change in absolute score by the baseline standard deviation. Mortality was analyzed using univariate and multivariate Cox regressions with baseline data as independent variables, calculating hazard ratios (HRs), 95\% CIs, and $p$ values. The rather large proportions of nonresponse for the two variables of cognitive speed and executive functions were handled through multiple imputations before the Cox regressions, using five automatic imputations in all missing values of the independent variables of the regressions, according to the method of fully conditional specification in SPSS (Liu and De, 2015). All the hypothesized independent variables and the sociodemographic variables of sex and educational level were selected for the multivariable Cox regression, using the enter method. The level of significance was set to $\alpha=0.05$. 
Table 1. Characteristics of study participants responding to GDS-15 at baseline $(n=371)^{\mathrm{a}}$

\begin{tabular}{|c|c|c|c|}
\hline & $\mathrm{ND}, N=249(\%)$ & SSD, $N=99(\%)$ & DEPR, $N=23(\%)$ \\
\hline \multicolumn{4}{|l|}{ Sociodemographic variables } \\
\hline Male sex, $n(\%)$ & $113(45.4)$ & $33(33.3)$ & $7(30.4)$ \\
\hline Education, mean $\mathrm{n}$ of years $(\mathrm{SD})$ & $8.6(3.7)$ & $8.4(3.5)$ & $8.1(2.5)$ \\
\hline Adapted housing ${ }^{\mathrm{b}} n(\%)$ & $9(3.6)$ & $17(17.2)$ & $5(21.7)$ \\
\hline Living alone, $n(\%)$ & $138(55.4)$ & $59(59.6)$ & $18(78.3)$ \\
\hline \multicolumn{4}{|l|}{ Functional variables } \\
\hline Loneliness, sometimes or often, $n(\%)$ & $71(29.7)$ & $50(52.6)$ & $19(86.4)$ \\
\hline Use of mobility assistive devices, $n(\%)$ & $92(36.9)$ & $72(72.7)$ & $19(82.6)$ \\
\hline Visual impairment, $n(\%)$ & $190(76.3)$ & $82(82.3)$ & $21(91.3)$ \\
\hline EQ-5D VAS, mean (SD) & $74(16)$ & $56(16)$ & $46(19)$ \\
\hline Basic ADLs, assistance need in clothing, $n(\%)$ & $9(3.8)$ & $16(16.8)$ & $3(13.6)$ \\
\hline I-ADLs, difficulties in cooking, $n(\%)$ & $42(16.9)$ & $47(47.5)$ & $15(65.2)$ \\
\hline MMSE, mean (SD) & $27(2.9)$ & $26(5.1)$ & $25(6.2)$ \\
\hline \multicolumn{4}{|l|}{ Other variables of psychiatric relevance } \\
\hline Somatic multimorbidity $\geq 2$ diseases, $n(\%)$ & $166(66.7)$ & $79(79.8)$ & $16(69.6)$ \\
\hline History of stroke, $n(\%)$ & $20(8.0)$ & $22(22.2)$ & $6(26.1)$ \\
\hline History of affective psychiatric disorder, $n(\%)$ & $18(7.2)$ & $20(20.2)$ & $8(34.8)$ \\
\hline History of anxiety disorder, $n(\%)$ & $7(2.8)$ & $11(11.1)$ & $4(17.4)$ \\
\hline Present use of tranquilizing medication, $n(\%)$ & $8(3.3)$ & $15(15.5)$ & $5(21.7)$ \\
\hline
\end{tabular}

GDS-15, Geriatric Depression Scale; SSD, subsyndromal depression; ND, non-depression; ADLs, activities of daily living; I-ADLs, instrumental activities of daily living; MMSE, Mini-Mental State Examination; SD, standard deviation; EQ, EuroQol; VAS, visual analog scale.

${ }^{a}$ A more thorough comparison of the baseline values for the three categories of depressive symptoms, including tests with logistic regression, is presented in Ludvigsson et al. (2016).

${ }^{\mathrm{b}}$ Adapted housing, i.e. sheltered housing, nursing home or dementia care.

\section{Results}

\section{Sample characteristics and missing data description}

Descriptive data of the participants at baseline are presented in Table 1. The distribution of the variables at baseline for each category of depressive symptoms has been described in more detail in a previous study (Ludvigsson et al., 2016). The participation rate gradually diminished (Figure 1) with each measure wave, with only $n=55(15 \%$ of $n=371$ at baseline) responding to GDS-15 at the 8-year follow-up.

Losses to follow-up were considered largely to be missing not at random, and factors significantly associated with attrition between each measure wave are presented in Table 2. The attrition was generally associated with adapted housing, lower levels of basic ADLs, I-ADLs, cognitive functions, and higher scores on GDS-15. Between T0 and T1, the attrition was also associated with female sex and lower educational level. The item nonresponse proportions ranged from $0 \%$ on most variables to higher proportions on the composite measures: $17 \%$ (64/371) missing on cognitive speed and 36\% (132/ 371 ) on executive function, numbers that were reduced by means of multiple imputations before the Cox regression analyses.

\section{Longitudinal morbidity in SSD compared with ND}

Table 3 shows the effect of SSD compared with ND over 8 years of follow-up on a number of outcome variables. Compared with ND, SSD was associated with higher morbidity in most of the hypothesized variables: functional abilities, self-perceived health status, social function, and mental health function. For example, in all measure waves, the presence of SSD instead of ND lowered the basic ADL scores of 0.58 points (standardized difference of 0.57 ) and lowered the I-ADLs scores of 5.4 points as a mean (standardized difference of 0.90). These effects on morbidity were still significant when adjusting for the time aspect and other potential confounders.

The effect of time or age on morbidity, on the other hand, was significant only for the variables of basic ADLs, MMSE, and I-ADLs where, for example, the 8-year movement from T1 to T4 meant a decrease of I-ADL score of 5.4 points as a mean (standardized difference of 0.90 ). The effect of SSD on cognitive functions was significant in the initial unadjusted analyses, but after adjusting for relevant factors the effect was no longer significant. Figure 2 shows the longitudinal development of the categories SSD and ND, and the participants with SSD compared with ND at age 85 showed a higher subsequent combined proportion of SSD and 
LOSS TO FOLLOW-UP BETWEEN LOSS TO FOLLOW-UP BETWEEN LOSS TO FOLLOW-UP BETWEEN LOSS TO FOLLOW-UP BETWEEN T0 AND T1 $(N=125)$ vs The T1 AND T2 $(N=91)$ vs The T2 And T3 $(N=177)$ vs The T3 AND T4 $(N=48)$ AT T3-T4 REST OF PARTICIPANTS AT T0 REST OF PARTICIPANTS AT T1 REST OF PARTICIPANTS AT T2 VS THE REST OF PARTICIPANTS

$$
(N=371) \quad(N=280)
$$

$$
(N=103)
$$

AT T3 $(N=55)$

\section{OUTCOME}

MEAN DIFFERENCE

MEAN DIFFERENCE

MEAN DIFFERENCE

MEAN DIFFERENCE

(Ci) or $\chi^{2}$ value $P$ Value (CI) OR $\chi^{2}$ value $P$ Value $\quad(\mathrm{CI})$ or $\chi^{2}$ value $P$ value (Ci) OR $\chi^{2}$ value

P VALUE

Male sex

Educational level

$n$ years

Adapted housing at

previous wave

Somatic

multimorbidity

\begin{tabular}{|c|c|c|c|c|c|c|}
\hline 0.013 & 0.75 & 0.387 & 1.1 & 0.290 & 1.7 & 0.192 \\
\hline 0.003 & $\begin{array}{c}-0.18 \\
(-1.0-0.65)\end{array}$ & 0.421 & $\begin{array}{c}-0.82 \\
(-1.8-0.11)\end{array}$ & 0.084 & $\begin{array}{c}-1.2 \\
(-2.7-0.40)\end{array}$ & 0.142 \\
\hline 0.001 & $7.8^{\mathrm{b}}$ & 0.005 & $4.0^{\mathrm{b}}$ & 0.046 & $5.3^{\mathrm{b}}$ & 0.021 \\
\hline - & $\begin{array}{c}-0.44 \\
(-0.80- \\
(-0.084)\end{array}$ & 0.016 & $\begin{array}{c}0.37 \\
(-0.015-0.75)\end{array}$ & 0.059 & $\begin{array}{c}0.018 \\
(-0.60-0.63)\end{array}$ & 0.953 \\
\hline - & $\begin{array}{c}-0.44 \\
(-0.77-(-0.11))\end{array}$ & 0.009 & $\begin{array}{c}-0.36 \\
(-0.61- \\
(-0.11))\end{array}$ & 0.005 & $\begin{array}{c}-0.94 \\
(-1.5- \\
(-0.36))\end{array}$ & 0.002 \\
\hline - & $\begin{array}{c}-2.3 \\
(-4.0-(-0.51)\end{array}$ & 0.012 & $\begin{array}{c}-4.0 \\
(-5.6-(-2.5))\end{array}$ & $<0.001$ & $\begin{array}{c}-6.1 \\
(-8.8-(-3.4)\end{array}$ & $<0.001$ \\
\hline 0.053 & $\begin{array}{c}-4.4 \\
(-9.5-0.78)\end{array}$ & 0.095 & $\begin{array}{c}-2.9 \\
(-7.0-1.1)\end{array}$ & 0.148 & $\begin{array}{c}-7.5 \\
(-15-0.046)\end{array}$ & 0.051 \\
\hline - & $\begin{array}{c}-0.85 \\
(-1.9-0.23)\end{array}$ & 0.123 & $\begin{array}{c}-2.0 \\
(-2.7-(-1.2))\end{array}$ & $<0.001$ & $\begin{array}{c}-1.9 \\
(-3.1- \\
(-0.69))\end{array}$ & 0.003 \\
\hline - & $\begin{array}{c}-0.14 \\
(-0.52-0.24)\end{array}$ & 0.464 & $\begin{array}{c}-0.94 \\
(-1.3-(-0.59))\end{array}$ & $<0.001$ & $\begin{array}{c}-0.52 \\
(-1.2-0.18)\end{array}$ & 0.145 \\
\hline - & $\begin{array}{c}-0.45 \\
(-0.99-0.10)\end{array}$ & 0.108 & $\begin{array}{c}-0.77 \\
(-1.2- \\
(-0.38))\end{array}$ & $<0.001$ & $\begin{array}{c}-0.74 \\
(-1.7-0.28)\end{array}$ & 0.149 \\
\hline 0.209 & $\begin{array}{c}0.21 \\
(-0.014-0.43)\end{array}$ & 0.066 & $\begin{array}{c}0.17 \\
(-0.061-0.41)\end{array}$ & 0.146 & $\begin{array}{c}0.11 \\
(-0.29-0.51)\end{array}$ & 0.586 \\
\hline - & $\begin{array}{c}0.59 \\
(0.027-1.1)\end{array}$ & 0.040 & $\begin{array}{c}0.62 \\
(0.15-1.1)\end{array}$ & 0.010 & $\begin{array}{c}0.86 \\
(-0.067-1.8)\end{array}$ & 0.069 \\
\hline - & 0.19 & 0.665 & $10^{\mathrm{d}}$ & 0.001 & 1.7 & 0.197 \\
\hline
\end{tabular}

$6.1^{2}$

Social functio
Mental health

$\mathrm{n}$ number of

diseases

$$
\begin{gathered}
-0.89 \\
(-1.5-(-0.30))
\end{gathered}
$$

$11^{\mathrm{b}}$

-

Functional abilities Basic ADLs

\section{I-ADLs}

$$
\begin{gathered}
-5.4 \\
(-11-0.066)
\end{gathered}
$$

MMSE

$$
-
$$

\section{Cognitive \\ speed}

Executive

function

$$
\begin{aligned}
& \text { Frequency of } \\
& \text { loneliness } \\
& \text { Depressive } \\
& \text { symptoms, } \\
& \text { GDS-15 } \\
& \text { score }
\end{aligned}
$$

\subsection{4}

$$
(-0.077-0.35)
$$

GDS-15, Geriatric Depression Scale; SSD, subsyndromal depression; ND, no
Examination; SD, standard deviation; EQ-VAS, EuroQol-visual analog scale.

Examination; SD, standard deviation; EQ-VAS, EuroQol-visual
Values in bold letters show significance at the level of $\alpha=0.05$.

${ }^{a}$ More women and fewer men among those lost to follow-up, a recurrent tendency in all the measure waves, though the association was significant only between $\mathrm{T} 0$ and $\mathrm{T} 1$.

${ }^{\mathrm{b}}$ More individuals with adapted housing and fewer with independent housing among those lost to follow-up.

${ }^{\mathrm{c}}$ No comparison possible, as the first measure wave of this variable was at $\mathrm{T} 1$.

$\mathrm{d}$ More with SSD and fewer with ND among those lost to follow-up. 
Table 3. Morbidity: Effect of SSD and time on different outcome variables over four measure waves and 8 years, according to calculations using linear mixed model analysis ${ }^{\mathrm{a}}, n=348$

\begin{tabular}{|c|c|c|c|c|c|c|c|}
\hline & & \multicolumn{2}{|c|}{$\begin{array}{c}\text { EFFECT OF SSD VS ND, } \\
\text { UNADJUSTED }\end{array}$} & \multicolumn{2}{|c|}{$\begin{array}{c}\text { EFFECT OF SSD VS ND, } \\
\text { ADJUSTED }^{\text {bc }}\end{array}$} & \multicolumn{2}{|c|}{ EFFECT OF TIME } \\
\hline \multicolumn{2}{|c|}{$\begin{array}{l}\text { OUTCOME VARIABLES } \\
\text { LONGITUDINALLY MEASURED }\end{array}$} & $\begin{array}{l}\text { PARAMETER } \\
\text { ESTIMATE (CI) }\end{array}$ & & $\begin{array}{l}\text { PARAMETER } \\
\text { ESTIMATE (CI) }\end{array}$ & & PARAMETER & \\
\hline \multirow[t]{2}{*}{$\begin{array}{l}\text { Functional } \\
\text { abilities }\end{array}$} & Basic ADLs & $\begin{array}{c}-0.62 \\
(-0.80-(-0.44))\end{array}$ & $<0.001$ & $\begin{array}{c}-0.58 \\
(-0.76-(-0.40))\end{array}$ & $<0.001$ & $\begin{array}{c}\text { T1-T4: }-0.56 \\
(-1.1-(-0.050))\end{array}$ & 0.032 \\
\hline & I-ADLs & $\begin{array}{c}-6.1 \\
(-7.1-(-5.1))\end{array}$ & $<0.001$ & $\begin{array}{c}-5.4 \\
(-6.4-(-4.4))\end{array}$ & $<0.001$ & $\begin{array}{l}\mathrm{T} 1-\mathrm{T} 4:-5.4 \\
(-7.4-(-3.4))\end{array}$ & $<0.001$ \\
\hline $\begin{array}{l}\text { Self-rated } \\
\text { health }\end{array}$ & EQ-VAS & $\begin{array}{c}-15 \\
(-17-(-12))\end{array}$ & $<0.001$ & $\begin{array}{c}-8.2 \\
(-11-(-5.5))\end{array}$ & $<0.001$ & $\begin{array}{l}\mathrm{T} 1-\mathrm{T} 4: 3.8 \\
(-0.19-7.7)\end{array}$ & 0.062 \\
\hline \multirow[t]{3}{*}{$\begin{array}{l}\text { Cognitive } \\
\text { functions }\end{array}$} & MMSE & $\begin{array}{c}-1.5 \\
(-2.1-(-0.089))\end{array}$ & $<0.001$ & $\begin{array}{c}-0.17 \\
(-0.42-0.75)\end{array}$ & 0.581 & $\begin{array}{l}\text { T1-T4: } 1.2 \\
(0.43-2.0)\end{array}$ & 0.003 \\
\hline & $\begin{array}{l}\text { Cognitive } \\
\text { speed }\end{array}$ & $\begin{array}{c}-0.19 \\
(-0.32-(-0.052))\end{array}$ & 0.006 & $\begin{array}{c}0.0086 \\
(-0.13-0.15)\end{array}$ & 0.902 & $\begin{array}{l}\text { T1-T4: } 0.19 \\
(-0.041-0.42)\end{array}$ & 0.106 \\
\hline & $\begin{array}{l}\text { Executive } \\
\text { function }\end{array}$ & $\begin{array}{c}-0.21 \\
(-0.37-(-0.053))\end{array}$ & 0.009 & $\begin{array}{c}-0.016 \\
(-0.18-0.15)\end{array}$ & 0.846 & $\begin{array}{l}\text { T1-T4: }-0.025 \\
(-0.25-0.30)\end{array}$ & 0.857 \\
\hline $\begin{array}{l}\text { Social } \\
\text { functions }\end{array}$ & $\begin{array}{l}\text { Frequency } \\
\text { loneliness }\end{array}$ & $\begin{array}{c}0.44 \\
(0.30-0.59)\end{array}$ & $<0.001$ & $\begin{array}{c}0.30 \\
(0.15-0.46)\end{array}$ & $<0.001$ & $\begin{array}{c}\text { T1-T4: } 0.00069 \\
(-0.32-0.32)\end{array}$ & 0.997 \\
\hline $\begin{array}{l}\text { Mental health } \\
\text { function }\end{array}$ & $\begin{array}{l}\text { Depressive } \\
\text { symptoms, } \\
\text { GDS-15 } \\
\text { score }\end{array}$ & $\begin{array}{c}1.8 \\
(1.5-2.2)\end{array}$ & $<0.001$ & $\begin{array}{c}1.1 \\
(0.62-1.6)\end{array}$ & $<0.001$ & $\begin{array}{l}\text { T2-T4: } 0.48 \\
(-0.13-1.1)\end{array}$ & 0.124 \\
\hline
\end{tabular}

GDS-15, Geriatric Depression Scale; SSD, subsyndromal depression; ND, non-depression; ADLs, activities of daily living; I-ADLs, instrumental activities of daily living; MMSE, Mini-Mental State Examination; SD, standard deviation; EQ-VAS, EuroQol-visual analog scale. Values in bold letters show significance at the level of $\alpha=0.05$.

${ }^{a}$ Diagonal covariance structure.

${ }^{\mathrm{b}}$ Adjusted for sex, somatic multimorbidity and time. Variables other than basic ADLs and I-ADLs also adjusted for I-ADLs.

${ }^{\mathrm{c}}$ A time by group interaction term was used as a fixed variable for the analyses, but this variable did not change the results significantly and was therefore left out for the final model.

${ }^{\mathrm{d}}$ Ordinal data for measure waves T1-T4, except for the variable depressive symptoms for which the longitudinal outcome corresponds only to measure waves $\mathrm{T} 2$ to $\mathrm{T} 4$, as the $\mathrm{T} 1$ value was the independent variable in the analysis.

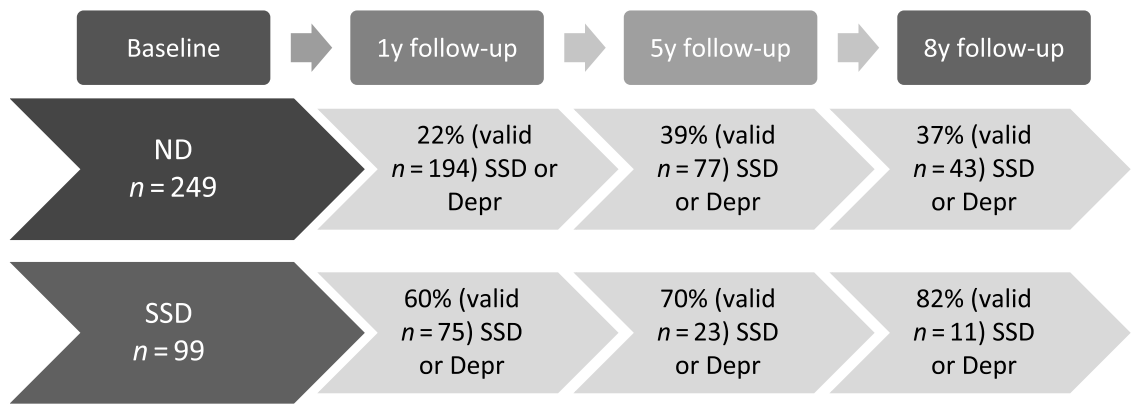

Figure 2. The longitudinal development of depressive symptoms: the combined proportion of subsyndromal depression (SSD) and depression in each measure wave, for individuals with non-depression (ND) compared with those with SSD at baseline (The proportions differed significantly in each measure wave for individuals with ND at baseline compared with those with SSD at baseline, with $\chi^{2}=37$ $(p<0.001)$ at 1-year follow-up, $\chi^{2}=6.7(p=0.010)$ at 5-year follow-up, and $\chi^{2}=7.0(p=0.008)$ at 8-year follow-up).

syndromal depression at each wave of follow-up, corresponding to a relatively greater morbidity in terms of depressive symptoms.

\section{Mortality in SSD compared with ND}

Table 4 shows mortality over 9 years of follow-up as a function of different independent variables at age 85 . All the presented variables except sex and educational level had a significant association with mortality, according to univariate regressions. The variable SSD compared with ND showed the largest effect size of the independent variables, with SSD increasing the risk of death 1.6 times.

When combining all the independent variables into a multivariable Cox regression, only three of the variables showed significant association with 
Table 4. Univariate and multivariate Cox regressions of all-cause mortality with baseline data as independent variables, $n=371^{\mathrm{a}}$

\begin{tabular}{|c|c|c|c|c|}
\hline & \multicolumn{2}{|c|}{ UNIVARIATE REGRESSION } & \multicolumn{2}{|c|}{ MULTIVARIATE REGRESSION ${ }^{\mathrm{b}}$} \\
\hline & HAZARD RATIO (CI) & $P$ VALUE & HAZARD RATIO (CI) & $P$ VALUE \\
\hline Male sex & $1.21(0.936-1.56)$ & 0.146 & $1.38(1.02-1.86)$ & 0.035 \\
\hline Education $n$ years & $0.999(0.965-1.04)$ & 0.963 & $1.01(0.969-1.05)$ & 0.698 \\
\hline Somatic multimorbidity ( $n$ diseases) & $1.13(1.05-1.22)$ & 0.002 & $1.07(0.981-1.16)$ & 0.130 \\
\hline SSD vs ND & $1.56(1.14-2.12)^{\mathrm{c}}$ & 0.005 & $0.915(0.298-2.81)^{\mathrm{d}}$ & 0.867 \\
\hline Depr vs ND & $1.31(0.753-2.29)^{\mathrm{e}}$ & 0.329 & $1.25(0.426-3.67)^{\mathrm{d}}$ & 0.674 \\
\hline Basic ADLs & $0.737(0.668-0.813)$ & $<0.001$ & $0.930(0.801-1.08)$ & 0.338 \\
\hline I-ADLs & $0.941(0.924-0.958)$ & $<0.001$ & $0.952(0.926-0.980)$ & 0.001 \\
\hline EQ-VAS & $0.991(0.984-0.998)$ & 0.012 & $1.08(0.997-1.02)$ & 0.161 \\
\hline MMSE & $0.952(0.929-0.976)$ & $<0.001$ & $1.03(0.978-1.09)$ & 0.238 \\
\hline Cognitive speed & $0.701(0.609-0.806)$ & $<0.001$ & $0.764(0.634-0.919)$ & 0.004 \\
\hline Executive function & $0.777(0.676-0.894)$ & 0.001 & $0.939(0.736-1.20)$ & 0.599 \\
\hline Loneliness $1-2^{\mathrm{f}}$ & $1.23(0.874-1.72)$ & 0.238 & $1.20(0.837-1.71)$ & 0.326 \\
\hline Loneliness $1-3^{f}$ & $1.52(1.01-2.11)$ & 0.012 & $1.38(0.939-2.02)$ & 0.101 \\
\hline Loneliness $1-4^{\mathrm{f}}$ & $1.18(0.646-2.14)$ & 0.595 & $1.07(0.525-2.19)$ & 0.850 \\
\hline
\end{tabular}

SSD, subsyndromal depression; ND, non-depression; ADLs, activities of daily living; I-ADLs, instrumental activities of daily living; MMSE, Mini-Mental State Examination; SD, standard deviation; EQ-VAS, EuroQol-visual analog scale; HR, hazard ratio.

Values in bold letters show significance at the level of $\alpha=0.05$.

${ }^{a}$ Final model built on $n 371$, whereas 238 (64\%) died, 133 (36\%) were censored. Five automatic imputations were done in every independent variable with missing data, according to the method fully conditional specification in SPSS. Number of imputed values was 64 in the variable cognitive speed, 132 in the variable executive function, and lower numbers in the rest of the variables. Cases available for the multiple Cox regression were $163 / 371(44 \%)$ before multiple imputation, and 371/371 (100\%) after multiple imputation.

${ }^{\mathrm{b}}$ The model was tested for proportional hazards, $p=0.889$.

${ }^{\mathrm{c}}$ Without imputations in this variable HR was $1.60(1.21-2.11)$ and $p=0.001$ in the univariate regression.

${ }^{\mathrm{d}}$ When using an alternative ordinal variable (including all the three categories ND, SSD, and Depr; without any imputed values) instead of the dichotomous variables (SSD vs ND) and (Depr vs ND), the results of the multivariate regression were $\mathrm{HR}=1.10(0.783-1.55)$ and $p=0.578$ for the categorical step ND-SSD, and HR $=1.03(0.508-2.09)$ and $p=0.936$ for the categorical step ND-Depr in the multivariate regression. ${ }^{\mathrm{e}}$ Without imputations in this variable, HR was $1.35(0.794-2.30)$ and $p=0.268$ in the univariate regression.

${ }^{f}$ The results for the variable loneliness are presented for each categorical step: 1-2 comparison never-seldom, 1-3 comparison neversometimes, 1-4 comparison never-often.

mortality, namely, male sex, lower cognitive speed, and lower I-ADLs.

\section{Discussion}

\section{Longitudinal morbidity in very old individuals with SSD}

We have examined the longitudinal outcomes of SSD in very old individuals, in a population-based sample of 85-year-old individuals who were followed for 8 years. SSD compared with ND was associated with all the hypothesized variables of morbidity, even though such association with cognitive functions was no longer significant when adjusting for potential confounders. SSD compared with ND at baseline was further associated with 1.6 times higher risk of mortality according to our univariate Cox regressions, but against our hypotheses the association was not significant after controlling for other relevant variables in the multivariate regression. As presented in the following discussion, the findings were mainly in line with previous studies on depression in very old individuals as well as with previous studies on
SSD in young old individuals (Blazer, 2003; Meeks et al., 2011).

The presence of SSD compared with ND was associated with lower levels of basic ADLs and I-ADLs over time, and the effect size was larger for I-ADLs compared to the former. These effect sizes were comparable to previous studies on younger individuals, though such effect sizes depend greatly on the type of measure (Schillerstrom et al., 2008). The association between depressive symptoms and ADLs over time has been described as complex though bidirectional, and a recent thorough analysis indicated that depressive symptoms drive $\mathrm{ADL}$ impairment more than vice versa (Hajek et al., 2017).

Also, the relation between cognitive functions and depressive symptoms has been described as bidirectional in both demented and nondemented study samples (Koenig et al., 2015). In this study, we found that SSD was associated with lower overall cognitive function as well as with lower cognitive speed and executive function over time but when adjusting for sex, somatic multimorbidity and I-ADLs, the association was not significant. Possibly the absence of a significant association in the latter was a result of 
selective losses to follow-up, as lower cognitive function was significantly associated with nonparticipation in consecutive measure waves. Other possible explanations would be that a real association was obscured by the selective survival of cognitively healthier individuals before the age of 85 or by competing risks from other causes in the oldest ages.

SSD was associated with lower self-perceived health and about equally strongly associated with frequency of loneliness over 8 years of follow-up, which was in line with the previous studies (Houtjes et al., 2014; Park et al., 2013). Regarding psychiatric outcomes, SSD was associated with higher levels of depressive symptoms over time, which was significant when adjusting for potential confounders. For those with SSD at baseline, the combined risk of SSD or depression at each consecutive measure wave was elevated compared with participants with ND at baseline, even when considering the higher risk of loss to follow-up. This finding is in accordance with the previous findings for SSD in younger ages, and with a dimensional view on affective disorders in which SSD and depression are adjacent states with a common origin (Beekman et al., 2002; Judd, 2012).

Our study did not show any significant association between time or age and depressive symptoms, and whether such an association really exists has been repeatedly investigated-several previous studies have shown that there is no such association when controlling for confounders and cohort effects (Blazer, 2000; Yang, 2007).

\section{Mortality in very old individuals with SSD}

Turning to the effect of SSD on mortality, the univariate Cox regression showed a rather strong association in terms of HR, which subsided when controlling for sex, somatic multimorbidity, I-ADLs and other factors of the multivariate regression. Most probably the interactions between depressive symptoms and different mediators of mortality are reciprocal in a complex system of mediators with sometimes synergistic effects on mortality (Schulz et al., 2002).

Previous studies have further shown a weaker or a nonexistent association between depressive symptoms and mortality in very old individuals, and a stronger association in younger ages (Cuijpers et al., 2013; Rapp et al., 2008). In contrast to the two previous studies by Rapp et al. and Stek et al., respectively, that have investigated the association between SSD and mortality in very old ages, we found that this association was significant when adjusting only for sex and comorbidity (Table S1 published as supplementary material online) (Rapp et al., 2008; Stek et al., 2005). However, in our study the association subsided when adding the covariate I-ADLs, and, therefore, our conclusion is (similar to the conclusion of Rapp et al.) that an independent association has been observed between SSD and mortality in lower ages, but not in the very old ages. Possible explanations for the difference between age-groups are selective survival, where individuals with depressive symptoms die earlier in life while more resilient individuals live longer, and also the dilution effects on the association as comorbidity and frailty increase with age and increase mortality independently (Vaughan et al., 2015). Maybe such dilution effects with increasing ages can explain why the association was not significant between SSD at baseline and mortality over the 9 years of follow-up in our study of very old individuals, when considering interacting factors.

\section{The significance of SSD for morbidity and mortality in the aged population}

The magnitudes of the association between SSD and the outcome variables were generally small in this study, for example, with percentage effects of the measure range 7 for basic ADLs and 23 for I-ADLs. However, the effects were clearly at significant levels; and in comparison with syndromal depression, the smaller effects of SSD on diverse outcomes at an individual level might mean a comparable effect for the population attributable fraction of the same conditions, due to a higher prevalence of SSD than of syndromal depression. The association between several longitudinal outcomes of morbidity and SSD compared with ND in our study indicates that the relatively mild condition of SSD has substantial influences on cognitive, functional, and psychosocial aspects of health, not only in younger adults but also in very old individuals. Interventions to prevent or treat SSD among very old individuals might correspondingly reduce these different aspects of morbidity.

Future studies could extend our understanding of possible causal aspects of the relationships between depressive symptoms and morbidity in old age by using tighter measure waves while also controlling for mediating factors clearly defined a priori. A more thorough analysis of single depressive symptoms could also improve the possibilities to disentangle moderators or relevant phenotypes in the heterogeneity of SSD and syndromal depression. In addition, there is a need for prevention studies of SSD in old individuals, to assess whether interventions might reduce morbidity, and to improve the quality of life (Gilbody et al., 2017). Regardless of whether SSD in old individuals is considered as pathology or normality (Ludvigsson et al., 2015), such interventions could possibly improve life and decrease the need of health care 
for many people, as SSD is common and the number of very old individuals is steadily increasing around the world.

\section{Limitations}

This study has several limitations. First, only $57 \%$ of the eligible population or $75 \%$ of the baseline participants responded to the GDS measurement, and systematical differences were observed between the responders and nonresponders. Therefore, the generalizability is limited, especially for certain subgroups of very old individuals, namely, females, those with adapted housing, higher educational level and lower ADL functions. Second, the subsequent attrition between the measure waves was substantial as in many longitudinal studies, with more attrition among individuals with lower levels of functions and higher levels of depressive symptoms. Even if the problem of missing data for some calculations was reduced with the multiple imputations method, the attrition probably had the consequence of falsely weakened association, though the exact proportions and directions of this selection bias were not estimated. The relatively small baseline sample sizes also limit the power of the results. Furthermore, SSD was defined by the screening instrument of GDS-15 instead of the Diagnostic and Statistical Manual of Mental Disorders, Fifth Edition classification registry, which is of relevance for the validity. The long time range of the study as well as the relatively large number of measure waves are the strengths of this study, while the rather long and irregular time intervals in between the waves limited the possibilities to make causal inferences.

\section{Conclusion}

This 8-year longitudinal study showed that morbidity in a population sample of 85-year-old individuals was significantly elevated in those with SSD compared with ND, even after controlling for relevant covariates. Mortality was also elevated in those with SSD according to univariate regressions, but this association vanished in multiple regressions. This contributes to previous diverging study results on the mortality of depressive symptoms in very old individuals and confirms previous results, showing that even mild depressive symptoms are associated with significant levels of morbidity in the population. The increasing proportions of very old individuals necessitate a better understanding of the consequences of the whole range of depressive symptoms in old individuals as well as studies on prevention and treatment in the subject area. Regardless of whether SSD is considered as pathology or normality, such interventions could possibly improve quality of life and reduce morbidity and the need for health care among many old people.

\section{Conflicts of interest}

The authors have no conflicts of interest to declare.

\section{Funding}

This project was supported by grants from Region Östergötland, Sweden. The funding source had no involvement in the study design, data collection, analysis, interpretation of the data, or in writing the manuscript.

\section{Description of authors' roles}

All authors contributed to the design of the study. Mikael Ludvigsson, Ewa Wressle, and Jan Marcusson collected the data. Mikael Ludvigsson managed the literature search and analyses. Mikael Ludvigsson and Anna Milberg undertook the statistical analyses and wrote the first draft of the manuscript. All authors contributed to and have approved the final manuscript.

\section{Acknowledgments}

We thank Mr Mats Fredriksson at Forum Östergötland, Linköping University, for help with the statistical analyses. This project was supported by grants from Region Östergötland, Sweden. The funding source had no involvement in the study design, data collection, analysis, interpretation of the data, or in writing the manuscript.

\section{Supplementary material}

To view supplementary material for this article, please visit https://doi.org/10.1017/S1041610219001480

\section{References}

Ayuso-Mateos, J.L., Nuevo, R., Verdes, E., Naidoo, N. and Chatterii, S. (2010). From depressive symptoms to depressive disorders: the relevance of thresholds. The British Fournal of Psychiatry, 196, 365-371. doi:10.1192/bjp. bp.109.071191. 
Bacon, K.L., Heeren, T., Keysor, J.J., Stuver, S.O., Cauley, J.A. and Fredman, L. (2016). Longitudinal and reciprocal relationships between depression and disability in older women caregivers and noncaregivers. Gerontologist, 56, 723-732. doi:10.1093/geront/gnu157.

Barry, L.C., Allore, H.G., Bruce, M.L. and Gill, T.M. (2009). Longitudinal association between depressive symptoms and disability burden among older persons. The Fournals of Gerontology Series A Biological Sciences and Medical Sciences, 64, 1325-1332. doi:10.1093/gerona/glp135.

Beekman, A.T. et al. (2002). The natural history of late-life depression: a 6-year prospective study in the community. Archives of General Psychiatry, 59, 605-611.

Blazer, D.G. (2000). Psychiatry and the oldest old. The American fournal of Psychiatry, 157, 1915-1924.

Blazer, D.G. (2003). Depression in late life: review and commentary. The fournals of Gerontology Series A Biological Sciences and Medical Sciences, 58, 249-265.

Callahan, C.M., Hui, S.L., Nienaber, N.A., Musick, B.S. and Tierney, W.M. (1994). Longitudinal study of depression and health services use among elderly primary care patients. Fournal of the American Geriatrics Society, 42, 833-838.

Cuijpers, P., Vogelzangs, N., Twisk, J., Kleiboer, A., Li, J. and Penninx, B.W. (2013). Differential mortality rates in major and subthreshold depression: meta-analysis of studies that measured both. The British fournal of Psychiatry, 202, 22-27. doi:10.1192/bjp.bp.112.112169.

de Craen, A.J., Heeren, T.J. and Gussekloo, J. (2003). Accuracy of the 15-item geriatric depression scale (GDS-15) in a community sample of the oldest old. International Fournal of Geriatric Psychiatry, 18, 63-66. doi:10.1002/gps. 773.

EuroQol Group (1990). EuroQol-a new facility for the measurement of health-related quality of life. Health Policy, 16, 199-208.

Folstein, M.F., Folstein, S.E. and McHugh, P.R. (1975). "Mini-mental state". A practical method for grading the cognitive state of patients for the clinician. Fournal of Psychiatric Research, 12, 189-198.

Fortin, M., Stewart, M., Poitras, M.E., Almirall, J. and Maddocks, H. (2012). A systematic review of prevalence studies on multimorbidity: toward a more uniform methodology. The Annals of Family Medicine, 10, 142-151. doi:10.1370/afm.1337.

Gilbody, S. et al. (2017). Effect of collaborative care vs usual care on depressive symptoms in older adults with subthreshold depression: the CASPER randomized clinical trial. The fournal of the American Medical Association, 317, 728-737. doi:10.1001/jama.2017.0130.

Grimby, G., Andren, E., Daving, Y. and Wright, B. (1998). Dependence and perceived difficulty in daily activities in community-living stroke survivors 2 years after stroke: a study of instrumental structures. Stroke, 29, 1843-1849.

Hajek, A. et al. (2017). Disentangling the complex relation of disability and depressive symptoms in old age - findings of a multicenter prospective cohort study in Germany. International Psychogeriatrics, 29, 885-895. doi:10.1017/ S1041610216002507.

Han, L., McCusker, J., Cole, M., Abrahamowicz, M. and Capek, R. (2008). 12-month cognitive outcomes of major and minor depression in older medical patients. The
American fournal of Geriatric Psychiatry, 16, 742-751. doi:10.1097/JGP.0b013e31817c6ad7.

Houtjes, W., van Meijel, B., van de Ven, P.M., Deeg, D., van Tilburg, T. and Beekman, A. (2014). The impact of an unfavorable depression course on network size and loneliness in older people: a longitudinal study in the community. International fournal of Geriatric Psychiatry, 29, 1010-1017. doi:10.1002/gps.4091.

Judd, L.L. (2012). Dimensional paradigm of the long-term course of unipolar major depressive disorder. Depression and Anxiety, 29, 167-171. doi:10.1002/da.21934.

Koenig, A.M. et al. (2015). Neuropsychological functioning in the acute and remitted states of late-life depression. Fournal of Alzheimer's Disease, 45, 175-185. doi:10.3233/ JAD-148006.

Laborde-Lahoz, P., El-Gabalawy, R., Kinley, J., Kirwin, P.D., Sareen, J. and Pietrzak, R.H. (2014).

Subsyndromal depression among older adults in the USA: prevalence, comorbidity, and risk for new-onset psychiatric disorders in late life. International fournal of Geriatric Psychiatry, 30, 677-685. doi:10.1002/gps.4204.

Liu, Y. and De, A. (2015). Multiple imputation by fully conditional specification for dealing with missing data in a large epidemiologic study. The International fournal of Statistics in Medical Research, 4, 287-295. doi:10.6000/19296029.2015.04.03.7.

Ludvigsson, M., Marcusson, J., Wressle, E. and Milberg, A. (2016). Markers of subsyndromal depression in very old persons. International fournal of Geriatric Psychiatry, 31, 619-628. doi:10.1002/gps.4369.

Ludvigsson, M., Milberg, A., Marcusson, J. and Wressle, E. (2015). Normal aging or depression? A qualitative study on the differences between subsyndromal depression and depression in very old people. Gerontologist, 55, 760-769. doi:10.1093/geront/gnt162.

Meeks, T.W., Vahia, I.V., Lavretsky, H., Kulkarni, G. and Jeste, D.V. (2011). A tune in "a minor" can "b major": a review of epidemiology, illness course, and public health implications of subthreshold depression in older adults. Fournal of Affective Disorders, 129, 126-142. doi:10.1016/j. jad.2010.09.015.

Nagga, K., Dong, H.J., Marcusson, J., Skoglund, S.O. and Wressle, E. (2012). Health-related factors associated with hospitalization for old people: comparisons of elderly aged 85 in a population cohort study. Archives of Gerontology and Geriatrics, 54, 391-397. doi:10.1016/j.archger.2011. 04.023.

Nordlund, A., Rolstad, S., Hellstrom, P., Sjogren, M., Hansen, S. and Wallin, A. (2005). The Goteborg MCI study: mild cognitive impairment is a heterogeneous condition. Fournal of Neurology Neurosurgery \& Psychiatry, 76, 1485-1490. doi:10.1136/jnnp.2004.050385.

Park, N.S., Jang, Y., Lee, B.S., Haley, W.E. and Chiriboga, D.A. (2013). The mediating role of loneliness in the relation between social engagement and depressive symptoms among older Korean Americans: do men and women differ? The fournals of Gerontology Series B Psychological Sciences and Social Sciences, 68, 193-201. doi:10.1093/geronb/gbs062.

Rabin, R. and de Charro, F. (2001). EQ-5D: a measure of health status from the EuroQol Group. Annals of Medicine, 33, 337-343. 
Rapp, M.A., Gerstorf, D., Helmchen, H. and Smith, J. (2008). Depression predicts mortality in the young old, but not in the oldest old: results from the Berlin Aging Study. The American fournal of Geriatric Psychiatry, 16, 844-852. doi:10.1097/JGP.0b013e31818254eb.

Regard, M. (1981). Cognitive rigidity and flexibility: a neuropsychological study. PhD dissertation. University of Victoria.

Reitan, R.M. (1992). Trail Making Test: Manual for Administration and Scoring. Tucson, AZ: Reitan Neuropsychology Laboratory.

Scafato, E. et al. (2012). Changes in severity of depressive symptoms and mortality: the Italian Longitudinal Study on Aging. Psychological Medicine, 42, 2619-2629. doi:10. 1017/S0033291712000645.

Schillerstrom, J.E., Royall, D.R. and Palmer, R.F. (2008). Depression, disability and intermediate pathways: a review of longitudinal studies in elders. Fournal of Geriatric Psychiatry and Neurology, 21, 183-197. doi:10.1177/ 0891988708320971.

Schulz, R., Drayer, R.A. and Rollman, B.L. (2002). Depression as a risk factor for non-suicide mortality in the elderly. Biological Psychiatry, 52, 205-225.
Sheikh, J.A. and Yeasavage, J.A. (1986). Geriatric Depression Scale (GDS): recent findings and development of a shorter version. In: T. L. Brink (Ed.), Clinical Gerontology: A Guide to Assessment and Intervention (pp. 165-173). New York: Howarth Press.

Stek, M.L., Vinkers, D.J., Gussekloo, J., Beekman, A.T., van der Mast, R.C. and Westendorp, R.G. (2005). Is depression in old age fatal only when people feel lonely? American fournal of Psychiatry, 162, 178-180. doi:10. 1176/appi.ajp.162.1.178.

Stek, M.L., Vinkers, D.J., Gussekloo, J., van der Mast, R.C., Beekman, A.T. and Westendorp, R.G. (2006). Natural history of depression in the oldest old: population-based prospective study. The British fournal of Psychiatry, 188, 65-69. doi:10.1192/bjp.188.1.65.

Vaughan, L., Corbin, A.L. and Goveas, J.S. (2015). Depression and frailty in later life: a systematic review. Clinical Interventions in Aging, 10, 1947-1958. doi:10. 2147/CIA.S69632.

Yang, Y. (2007). Is old age depressing? Growth trajectories and cohort variations in late-life depression. Fournal of Health and Social Behavior, 48, 16-32. doi:10.1177/ 002214650704800102. 